\title{
Effects of caffeine on time to exhaustion in exercise performed below and above the anaerobic threshold
}

B.S. Denadai and M.L.D.R. Denadai
Departamento de Educação Física, Instituto de Biociências, Universidade Estadual Paulista, Rio Claro, SP, Brasil

\section{Correspondence \\ B.S. Denadai \\ Departamento de Educação Física Instituto de Biociências, UNESP \\ Avenida 24-A, 1515 \\ 13506-900 Rio Claro, SP \\ Brasil \\ Research supported by FUNDUNESP and CNPq. Publication supported byFAPESP.}

Received March 26, 1997 Accepted January 19, 1998

\section{Abstract}

Controversy still exists concerning the potential ergogenic benefit of caffeine (CAF) for exercise performance. The purpose of this study was to compare the effects of CAF ingestion on endurance performance during exercise on a bicycle ergometer at two different intensities, i.e., approximately $10 \%$ below and $10 \%$ above the anaerobic threshold (AT). Eight untrained males, non-regular consumers of CAF, participated in this study. AT, defined as the intensity (watts) corresponding to a lactate concentration of $4 \mathrm{mM}$, was determined during an incremental exercise test from rest to exhaustion on an electrically braked cycle ergometer. On the basis of these measurements, the subjects were asked to cycle until exhaustion at two different intensities, i.e., approximately $10 \%$ below and $10 \%$ above AT. Each intensity was performed twice in a double-blind randomized order by ingesting either CAF ( $5 \mathrm{mg} / \mathrm{kg}$ ) or a placebo (PLA) $60 \mathrm{~min}$ prior to the test. Venous blood was analyzed for free fatty acid, glucose, and lactate, before, during, and immediately after exercise. Rating of perceived exertion and time to exhaustion were also measured during each trial. There were no differences in free fatty acids or lactate levels between CAF and PLA during and immediately after exercise for either intensity. Immediately after exercise glucose increased in the CAF trial at both intensities. Rating of perceived exertion was significantly lower $(\mathrm{CAF}=14.1 \pm 2.5 v s$ PLA $=16.6 \pm$ $2.4)$ and time to exhaustion was significantly higher $(\mathrm{CAF}=46.54 \pm$ $8.05 \mathrm{~min} v s \mathrm{PLA}=32.42 \pm 14.81 \mathrm{~min}$ ) during exercise below AT with $\mathrm{CAF}$. However, there was no effect of CAF treatment on rating of perceived exertion $(\mathrm{CAF}=18.0 \pm 2.7$ s $\mathrm{PLA}=17.6 \pm 2.3)$ and time to exhaustion $(\mathrm{CAF}=18.45 \pm 7.28 \mathrm{~min} v s \mathrm{PLA}=19.17 \pm 4.37 \mathrm{~min})$ during exercise above AT. We conclude that in untrained subjects caffeine can improve endurance performance during prolonged exercise performed below AT and that the decrease of perceived exertion can be involved in this process.
Key words

- Caffeine

- Anaerobic threshold

- Endurance

- Lactate

- Perceived exertion 
The possible ergogenic effects of caffeine (CAF) on exercise performance have served as the basis for a large number of studies. However, there are still controversies about the conditions under which caffeine is capable of modifying performance, as well as concerning its possible mechanisms of action due to the absence of standardization among the various experimental procedures. Furthermore, the action of caffeine depends on the type, intensity and duration of exercise, nutritional and training status, the dose of caffeine, environmental conditions, and individual variations $(1,2)$.

Specifically concerning exercise intensity, Jacobson and Kulling (3) have suggested that caffeine may be capable of increasing the time of endurance only when the effort is performed at intensities that allow individuals to exercise for more than one hour. Normally, exercises that can be performed beyond this period of time show intensities below the anaerobic threshold (AT) (4), suggesting that caffeine may modify performance only in exercises below this intensity. Most studies analyzing the effects of caffeine on time of endurance used relative loads to maximum oxygen consumption $\left(\% \mathrm{VO}_{2} \max \right)(5,6)$, while there are no studies with exercise intensities relative to the AT. Since AT can present values between $35 \%$ and $90 \%$ of $\mathrm{VO}_{2} \max (7)$, it is not possible to affirm that, in studies in which the ergogenic effect of caffeine was found or not, subjects were below or above AT, respectively. Thus, the objective of the present study was to determine the effects of caffeine $(5 \mathrm{mg} / \mathrm{kg})$ on the time of endurance and rate of perceived exertion during exercise performed below and above AT.

Eight males (age: $20.4 \pm 2.3$ years; height: $172 \pm 8.3 \mathrm{~cm}$; weight: $75.4 \pm 9.4 \mathrm{~kg}$ ), nonregular consumers of caffeine, gave their written consent to participate in the study. All volunteers were classified as untrained individuals, i.e., individuals not engaged in regular physical activity or sport.
Anaerobic threshold was defined as the intensity (watts; W) corresponding to a lactate concentration of $4 \mathrm{mM}$ and was determined using a progressive test conducted on an electromagnetically braked cycle ergometer. The initial workload was $25 \mathrm{~W}$ and the intensity was increased by $25 \mathrm{~W}$ every $5 \mathrm{~min}$ until exhaustion. At the end of each stage, 25 $\mu \mathrm{l}$ of blood was collected from the ear lobe, into microcentrifuge tubes containing $50 \mu \mathrm{l}$ $\mathrm{NaF}(1 \%)$. The intensity at $4 \mathrm{mM}$ lactate concentration was calculated by linear interpolation (8).

Following AT testing, the subjects reported to the laboratory on four occasions for treatments that were randomized for each subject. Each subject completed the four experimental treatments within a 3-4-week period. Subjects maintained their normal dietary habits and were asked not to drink coffee or caffeine-containing drinks for $24 \mathrm{~h}$ before each experiment. On the basis of AT measurement, the subjects were asked to cycle until exhaustion at two different intensities: approximately $10 \%$ below and $10 \%$ above AT. The test was stopped when subjects could no longer maintain pedalling at $50 \mathrm{rpm}$. Each intensity was performed twice in a double-blind randomized order with the subject ingesting either CAF $(150 \mathrm{ml}$ of hot water containing $5 \mathrm{~g}$ of decaffeinated coffee and caffeine $(5 \mathrm{mg} / \mathrm{kg}))$ or a placebo (PLA; $150 \mathrm{ml}$ of hot water containing $5 \mathrm{~g}$ of decaffeinated coffee) $60 \mathrm{~min}$ prior to the test. Possible discrimination between $\mathrm{CAF}$ and PLA was eliminated by addition of an artificial sweetener to the beverages (9).

Venous blood was sampled from a venous catheter in a forearm vein immediately before each trial $(0 \mathrm{~min})$, after $10 \mathrm{~min}$ of exercise, and immediately after exercise, and subsequently analyzed for serum free fatty acids (FFA) (10), glucose (11) and caffeine (12). Lactate was measured by an electrochemical method (YSI 2300 STAT). During the experimental trial, rating of perceived exertion (RPE) and heart rate (Polar Vantage 
XL) were recorded every $5 \mathrm{~min}$. RPE was assessed by the Borg scale (13). Time to exhaustion was also measured during each trial.

Results are reported as means $\pm \mathrm{SD}$. Plasma caffeine and time to exhaustion were analyzed by the Student $t$-test and other data were analyzed using repeated measures twoway ANOVA for time and treatment effects. Whenever necessary, the means were compared by the Tukey test. Statistical significance was set at $\mathrm{P}<0.05$.

Plasma caffeine was significantly higher in the CAF situation than in the PLA situation at both intensities (Table 1). Time to exhaustion was significantly higher in the CAF than in the PLA situation, but only during exercise below AT (Table 1).

The results of FFA, glucose and lactate concentrations are shown in Table 2. Compared to PLA, the CAF treatment increased plasma FFA levels immediately before $(0$ min), but not during or immediately after exercise, for both intensities. FFA levels increased significantly $(\mathrm{P}<0.05)$ over time of exercise in the PLA and CAF situations, but only during exercise below AT (Table 2).

Table 1 - Effect of caffeine on plasma caffeine concentration and time to exhaustion.

Data are reported as means \pm SD for plasma caffeine concentration immediately before exercise and for time to exhaustion for the experimental conditions caffeine (CAF; $5 \mathrm{mg} / \mathrm{kg}$ ) and placebo (PLA) during exercise below (BAT) and above (AAT) the anaerobic threshold. ${ }^{*} \mathrm{P}<0.05$ compared to PLA at the same intensity of exercise for $\mathrm{N}=8$ (Student $t$-test).

\begin{tabular}{lcc}
\hline & $\begin{array}{c}\text { Plasma caffeine } \\
(\mu \mathrm{g} / \mathrm{ml})\end{array}$ & $\begin{array}{c}\text { Time to exhaustion } \\
(\mathrm{min})\end{array}$ \\
\hline PLA-BAT & 0 & $32.42 \pm 14.81$ \\
CAF-BAT & $6.5 \pm 1.2^{*}$ & $46.54 \pm 8.05^{*}$ \\
PLA-AAT & 0 & $19.17 \pm 4.37$ \\
CAF-AAT & $6.3 \pm 1.4^{*}$ & $18.45 \pm 7.28$
\end{tabular}

Table 2 - Effect of caffeine on free fatty acids, glucose, lactate, heart rate, and rate of perceived exertion at rest and during exercise.

Data are reported as means \pm SD for free fatty acids (FFA), glucose (GLUC), lactate (LAC), heart rate (HR) and rate of perceived exertion (RPE) immediately before exercise (0), at $10 \mathrm{~min}$ of exercise (10), and immediately after exercise (IPE) under the experimental conditions involving caffeine (CAF; $5 \mathrm{mg} / \mathrm{kg}$ ) and placebo (PLA), during exercise below (BAT) and above (AAT) the anaerobic threshold. ${ }^{*} \mathrm{P}<0.05$ compared to PLA at the same time and intensity of exercise. ${ }^{* *} \mathrm{P}<0.05$ compared to $0 \mathrm{~min}$ in the same condition. $+\mathrm{P}<0.05$ compared to 10 min in the same condition ( $\mathrm{N}=8$ ) (two-way ANOVA + Tukey test).

\begin{tabular}{llllcc}
\hline & FFA $(\mathrm{mEq} / \mathrm{l})$ & GLUC $(\mathrm{mg} / 100 \mathrm{ml})$ & LAC $(\mathrm{mM})$ & $\mathrm{HR}(\mathrm{bpm})$ & $\mathrm{RPE}$ \\
\hline PLA-BAT & & & & & \\
0 & $0.13 \pm 0.05$ & $71.5 \pm 8.4$ & $0.6 \pm 0.1$ & $68.5 \pm 6.5$ & - \\
10 & $0.11 \pm 0.04$ & $69.7 \pm 9.2$ & $2.8 \pm 0.4^{* *}$ & $148.5 \pm 19.0^{* *}$ & $13.3 \pm 1.1$ \\
IPE & $0.26 \pm 0.19^{* *}$ & $64.4 \pm 3.7$ & $2.8 \pm 0.5^{* *}$ & $157.8 \pm 21.5^{* *}$ & $16.6 \pm 2.4^{+}$ \\
CAF-BAT & & & & \\
0 & $0.24 \pm 0.06^{*}$ & $85.6 \pm 16.0$ & $0.8 \pm 0.1$ & $70.2 \pm 6.7$ & - \\
10 & $0.14 \pm 0.06$ & $71.8 \pm 8.3$ & $3.1 \pm 0.6^{* *}$ & $143.5 \pm 13.4^{* *}$ & $11.5 \pm 1.7^{*}$ \\
IPE & $0.38 \pm 0.16^{* *}$ & $86.8 \pm 9.7^{*}$ & $3.2 \pm 0.6^{* *}$ & $153.8 \pm 12.2^{* *}$ & $14.1 \pm 2.5^{*+}$ \\
PLA-AAT & & & & & \\
0 & $0.16 \pm 0.08$ & $78.9 \pm 4.0$ & $0.8 \pm 0.3$ & $67.3 \pm 5.9$ & - \\
10 & $0.15 \pm 0.10$ & $68.2 \pm 4.7$ & $4.8 \pm 1.3^{* *}$ & $166.5 \pm 13.4^{* *}$ & $14.8 \pm 2.5$ \\
IPE & $0.21 \pm 0.13$ & $69.5 \pm 10.5$ & $5.8 \pm 1.1^{* *+}$ & $173.1 \pm 13.0^{* *}$ & $17.6 \pm 2.3^{+}$ \\
CAF-AAT & & & & & \\
0 & $0.26 \pm 0.09^{*}$ & $81.1 \pm 8.3$ & $0.8 \pm 0.2$ & $70.9 \pm 8.1$ & - \\
10 & $0.17 \pm 0.06$ & $75.6 \pm 9.9$ & $4.9 \pm 1.4^{* *}$ & $170.8 \pm 16.1^{* *}$ & $14.6 \pm 2.5$ \\
IPE & $0.17 \pm 0.13$ & $86.2 \pm 9.9^{*}$ & $6.0 \pm 1.0^{* *+}$ & $177.0 \pm 13.0^{* *}$ & $18.0 \pm 2.7^{+}$ \\
& & & & &
\end{tabular}


CAF treatment was observed to increase plasma glucose concentration only at the end of exercise for both intensities. There was no effect of exercise duration on glucose concentration for either treatment or intensity (Table 2). There were no significant differences in plasma lactate concentration between CAF and PLA treatments at either intensity. However, a significant increase in plasma lactate concentration occurred over time in both treatments and at both intensities (Table 2).

The results of heart rate and RPE are shown in Table 2. There were no differences in exercise heart rate between CAF and PLA treatments for either intensity. However, exercise heart rate increased significantly $(\mathrm{P}<0.05)$ over time of exercise at both intensities (Table 2). RPE was always higher in the PLA situation than in the CAF situation, but only during exercise below AT. RPE increased significantly over time of exercise in both situations and at both intensities (Table 2).

In order to study the effects of caffeine on time of endurance during exercise under different metabolic conditions (with and without lactate steady-state), the present study used the AT concept proposed by Heck et al. (8) to determine exercise intensity. According to this concept, the 4-mM concentration corresponds to the highest intensity of effort where lactate steady-state can exist. In the present study, the lactate concentration behaved according to Heck's concept, i.e., for exercise intensity below AT a steady-state phase was found, while such phase did not show up at intensity above AT (Table 2). Thus, the effects of caffeine could be studied under the two metabolic conditions (below and above AT).

In spite of some contradictory results in the literature, Jacobson and Kulling (3) proposed that caffeine increases the time to reach exhaustion only in endurance exercises that can be sustained for more than 60 min. In the first instance, this may suggest that caffeine would only act as an ergogenic resource during an exercise performed below AT, since the duration of effort above this intensity is quite reduced (4).

The present results confirm that, at least in untrained individuals, caffeine can increase performance only in exercise below AT, although the period of effort without caffeine did not exceed 35 min.

The existence of ergogenic effects on endurance time only during exercise performed below AT can be explained by at least two different mechanisms.

Firstly, exercise performed above AT results in accumulation of organic acid metabolites, which can impair mitochondrial enzyme activity, thus reducing energy production and therefore exercise duration (5). Under these conditions, the rate of muscle glycogen utilization is high, although a certain amount still remains in muscle after exhaustion (14). However, in exercise performed below AT there is no lactate accumulation and exercise duration can be limited by glycogen depletion, which limits energy production, since carbohydrates are essential to Krebs cycle function (15). Since many studies $(5,16)$, but not all of them (9), have demonstrated that caffeine can increase intramuscular triacylglycerol and/or extramuscular FFA, there may be a glycogen economy (Randle effect) retarding the beginning of exhaustion only during exercise performed below AT. For exercise performed above AT, the enhanced FFA supply caused by caffeine probably does not cause any ergogenic benefit, because utilization of this substrate at this intensity is small (17). Moreover, exhaustion does not seem to occur due to the depletion of glycogen sources. Some studies have found muscular glycogen economy during endurance exercise after caffeine ingestion $(15,18)$.

However, in our study, except during rest (0 min), caffeine did not modify FFA concentration for either effort intensity (below and above AT). This result is in agreement 
with other studies (16) and does not necessarily show that there was no increase in FFA oxidation after caffeine ingestion, because FFA concentration measurement does not seem to provide definitive evidence of FFA flow and oxidation during exercise (1).

Another mechanism that has been proposed is that the ergogenic effect of caffeine may occur due to neuromuscular function improvement. These modifications may occur at relatively small plasma caffeine levels $(100 \mu \mathrm{M})$, which are reached after ingestion of only 1-3 cups of coffee (100 to $300 \mathrm{mg}$ of caffeine) (2). At the central nervous system (CNS) level, the hypothesis of neuromuscular improvement is based on studies that have demonstrated a reversal of adenosineinduced depression of synaptic transmission by caffeine in the rat brain cortex (19). More- over, some studies have shown that caffeine can reduce the excitation threshold of CNS neurons (20). Thus, it is possible that these effects in the CNS facilitate the recruitment of motor units and/or diminish perception of fatigue during exercise. These modifications may be responsible for the lower RPE found in some studies (5). Since in our study caffeine was only capable of diminishing RPE during exercise performed below AT, it is possible that the increase in time of endurance occurred due to a reduction of RPE.

\section{Acknowledgments}

The authors are grateful to Angelina Zanesco, E. Custódio and J.R.R. Silva for technical assistance.

\section{References}

1. Graham TE, Rush JWE \& Soeren $\mathrm{MH}$ (1994). Caffeine and exercise: Metabolism and performance. Canadian Journal of Applied Physiology, 19: 111-138.

2. Nehlig A \& Debry G (1994). Caffeine and sports activity: A review. International Journal of Sports Medicine, 15: 215-223.

3. Jacobson BH \& Kulling FA (1989). Health and ergogenic effects of caffeine. British Journal of Sports Medicine, 23: 34-40.

4. Kindermann W, Simon G \& Keul J (1979). The significance of the aerobic-anaerobic transition for the determination of work load intensities during endurance training. European Journal of Applied Physiology, 42: 25-34.

5. Costill DL, Dalsky GP \& Fink WJ (1978). Effects of caffeine ingestion on metabolism and exercise performance. Medicine and Science in Sports and Exercise, 10: 155-158.

6. Graham TE \& Spriet LL (1991). Performance and metabolic response to a high caffeine dose during exercise. Journal of Applied Physiology, 71: 2292-2298.

7. Mader A \& Heck H (1986). A theory of the metabolic origin of "anaerobic threshold". International Journal of Sports Medicine, 7: 45-65.
8. Heck H, Mader A, Hess G, Mucke R, Muller R \& Hollman W (1985). Justification of the $4 \mathrm{mmol} / \mathrm{l}$ lactate threshold. International Journal of Sports Medicine, 6: 117-130.

9. Casal DC \& Leon AS (1985). Failure of caffeine to affect substrate utilization during prolonged running. Medicine and Science in Sports and Exercise, 17: 174-179.

10. Regow BJM, Cornelissen PJHC, Spijkers JBF \& Weeber YMM (1971). Specific determination of free fatty acid in plasma. Clinica Chimica Acta, 31: 187-195.

11. Marks V (1959). An improved glucoseoxidase method for determination of blood, C.S.F., and urine levels. Clinica Chimica Acta, 4: 395-399.

12. Routh JI, Shane NA, Arredondo EG \& Paul WD (1969). Determination of caffeine in serum and urine. Clinical Chemistry, 15: 661-668.

13. Borg GA (1973). Perceived exertion: a note on history and methods. Medicine and Science in Sports and Exercise, 5: 9093.

14. Saltin B \& Karlsson J (1975). Muscle glycogen utilization during work of different intensities. Advances in Experimental Medicine and Biology, 18: 289-299.
15. Hermansen L, Hultman E \& Saltin $B$ (1967). Muscle glycogen use during prolonged severe exercise. Acta Physiologica Scandinavica, 71: 129-139.

16. Essig D, Costill DL \& Van Handel PJ (1980). Effects of caffeine ingestion on utilization of muscle glycogen and lipid during leg ergometer cycling. International Journal of Sports Medicine, 1: 8690.

17. O'Brien MJ, Viguie CA, Mazzeo RS \& Brooks GA (1993). Carbohydrate dependence during marathon running. Medicine and Science in Sports and Exercise, 25: 1009-1017.

18. Spriet LL, MacLean DA, Dyck DJ, Hultman E, Caderblad G \& Graham TE (1992). Caffeine ingestion and muscle metabolism during exercise in humans. American Journal of Physiology, 262: 891-898.

19. Phillis JW \& Wu PH (1981). The role of adenosine and its nucleotides in central synaptic transmission. Progress in Neuroscience, 16: 187-239.

20. Waldeck B (1973). Sensitization by caffeine of central catecholamine receptors. Journal of Neural Transmission, 34: 6172. 